\title{
Carotid Stenting in Asymptomatic Carotid Stenosis: The Calgary Experience
}

\author{
N. Shobha, M.A. Almekhlafi, A. Pandya, P.L. Couillard, W.F. Morrish, J.H. Wong, \\ M.D. Hill
}

\begin{abstract}
Background: Although carotid endarterectomy is considered the 'gold standard' for standard risk symptomatic patients, the treatment of choice for asymptomatic patients remains controversial. Carotid stenting has demonstrated real-world outcomes consistent with established guidelines for carotid endarterectomy in asymptomatic high-surgical risk patients in recent prospective multicenter trials. We describe our experience with asymptomatic patients who underwent carotid stenting at our center in a routine clinical setting. Methods: This is a retrospective, longitudinal cohort study of patients who underwent carotid angioplasty and stenting at the Foothills Medical Center, Calgary, Canada between 1997 and 2007. The qualifying events were categorized as symptomatic and asymptomatic. The procedures were performed by four experienced neurointerventionists. The primary outcome was stroke or death at 30-day follow- up. Results: 243 patients underwent 255 carotid stenting procedures. Their ages ranged from 50 to 83 years; the mean age was $72.0 \pm 9.3$ years; $67(26.3 \%)$ were women. Forty one patients $(16.1 \%)$ were asymptomatic; 214 patients $(83.9 \%)$ were symptomatic. The patients in the asymptomatic group were significantly younger - $66.0 \pm 8.8$ years compared to patients in the symptomatic group $73.2 \pm 8.9$ years ( $<0.0001)$. Intraprocedurally one minor stroke $(2.4 \%)$ occurred in the asymptomatic group. At 30 day follow-up, no deaths or further strokes were noted in the asymptomatic group; while eight deaths, six major and seven minor strokes occurred in the symptomatic group $(\mathrm{p}=0.22)$. Conclusion: Carotid stenting appears to be a safe procedure in asymptomatic patients with severe carotid stenosis in routine clinical settings as witnessed in this single center study.
\end{abstract}

RÉSUMÉ: Implantation d'endoprothèse dans le traitement de la sténose carotidienne asymptomatique : l'expérience de Calgary. Contexte : Bien que l'endartérectomie carotidienne soit considérée comme la méthode de référence chez les patients symptomatiques à risque usuel, le traitement de choix chez les patients asymptomatiques demeure un sujet de controverse. Les résultats de la mise en place d'une endoprothèse carotidienne en pratique courante sont conformes aux lignes directrices établies pour l'endartérectomie carotidienne chez les patients asymptomatiques dont le risque chirurgical est élevé, qui ont participé à des essais multicentres prospectifs récents. Nous décrivons notre expérience chez des patients asymptomatiques qui ont subi une implantation d'endoprothèse de la carotide à notre centre hospitalier dans un contexte clinique de routine. Méthodes : Il s'agit d'une étude longitudinale rétrospective de cohorte de patients qui ont subi une angioplastie carotidienne avec implantation d'endoprothèse au Foothill Medical Center, à Calgary, au Canada, entre 1997 et 2007. Les événements qui motivaient l'intervention ont été classés selon la présence ou l'absence de symptômes. Quatre neurointerventionnistes expérimentés ont réalisé les interventions. L’issue primaire était l'accident vasculaire cérébral ou le décès au cours des trente premiers jours de suivi. Résultats : Deux cent quarante-trois patients ont subi 255 implantations d'endoprothèses. Les patients étaient âgés de 50 à 83 ans, avaient un âge moyen de 72,0 $\pm 9,3$ ans, et 67 (26,3\%) étaient des femmes. Quarante et un patients (16,1\%) étaient asymptomatiques et $214(83,9 \%)$ étaient symptomatiques. Les patients du groupe asymptomatique, dont l'âge moyen était de 66,0 $\pm 8,8$ ans, étaient significativement plus jeunes par rapport aux patients du groupe symptomatique dont l'âge moyen était de 73,2 $\pm 8,9$ ans (p < 0,0001). Un patient asymptomatique $(2,4 \%)$ a subi un AVC mineur pendant l'intervention. Au moment du suivi 30 jours après l'intervention, aucun décès ou autre AVC n'a été observé dans le groupe de patients asymptomatiques alors que 8 décès, $6 \mathrm{AVC}$ majeurs et $7 \mathrm{AVC}$ mineurs sont survenus chez les patients du groupe symptomatique $(\mathrm{p}=0,22)$. Conclusion : L'implantation d'une endoprothèse au niveau de la carotide semble une intervention sûre chez les patients asymptomatiques qui sont porteurs d'une sténose sévère de la carotide dans un contexte de soins de routine, comme le témoigne cette étude réalisée dans un seul centre.

Can. J. Neurol. Sci. 2010; 37: 568-573

Stroke is a leading cause of death and disability ${ }^{1}$ with $8 \%$ to $29 \%$ of all ischemic strokes caused by extracranial atherosclerotic disease. ${ }^{2}$ Despite advances in the acute management of stroke, prevention remains the best and most cost effective means of reducing the stroke burden in the community. ${ }^{3}$ The annual incidence of stroke in patients with stenosis $>80 \%$ is $5-6 \% .{ }^{4}$ Carotid endarterectomy is an effective procedure to prevent stroke in symptomatic patients with severe carotid stenosis. ${ }^{5}$ An initial US study in 1993 showed that carotid endarterectomy reduced the overall incidence of ipsilateral neurologic events among a selected group of male patients with asymptomatic carotid stenosis. ${ }^{6}$ The largest trial of patients with asymptomatic carotid stenosis of 60 to 99 percent found an absolute reduction of 5.9 percent in the risk of stroke at five years, and suggested superior results for carotid endarterectomy

From the Departments of Clinical Neurosciences (NS, MAA, AP, PLC, JHW, MDH),

Community Health Sciences (MDH), Diagnostic Imaging (WFM, JHW, MDH), and

Medicine (MDH); University of Calgary, Calgary, Alberta, Canada.

Received February 16, 2010. Final Revisions Submitted April 15, 2010. Correspondence to: Michael D. Hill, University of Calgary, Dept Clinical

Neurosciences \& Hotchkiss Brain Institute, Rm 1242A, Foothills Medical Centre,

1403 29th Street NW, Calgary, Alberta, T2N 2T9, Canada. 
combined with aspirin compared to aspirin and risk factor reduction alone in preventing ipsilateral stroke in asymptomatic male patients with internal carotid artery (ICA) stenosis of $60 \%$ or more. ${ }^{7}$ These results were replicated in the British Asymptomatic Carotid Surgery Trial (ACST). ${ }^{8}$

However, both of these large studies have been critiqued. Any benefit for asymptomatic carotid endarterectomy is accrued over years and must be balanced carefully against the immediate procedural risk. Since the average annual risk reduction is small, surgical therapy must have a periprocedural complication rate that is generally estimated at $3 \%$ or less. In Canada, this riskbenefit trade-off means that in most cases of asymptomatic carotid stenosis, medical therapy is favored. ${ }^{9}$

With the evolution of carotid stenting and its growing use worldwide, carotid stenting is being used for stroke prevention in asymptomatic carotid stenosis patients. In randomized trials of stenting vs. endarterectomy among symptomatic patients, endarterectomy appears to have a better safety record on 30-day outcomes. The CAVATAS ${ }^{10}$ and SAPPHIRE ${ }^{11}$ trials found no significant differences in the 30-day outcomes of carotid stenting compared to carotid endarterectomy, although half of the SAPPHIRE population was composed of asymptomatic patients and CAVATAS was largely an angioplasty only (rather than angioplasty and stenting) study. Three European trials (ICSS, SPACE and EVA-3S) among symptomatic carotid stenosis patients showed that carotid endarterectomy had a lower periprocedural complication rate. ${ }^{12-14}$ The differences were most marked in EVA-3S, very modest in SPACE $(0.5 \%)$ and in ICSS driven largely by nondisabling strokes associated with stenting, a finding that may have been balanced to some degree, by a much higher frequency of disabling cranial nerve palsy seen with endarterectomy. It does appear from these studies of symptomatic patients that carotid stenting is at least as durable as carotid endarterectomy in preventing stroke out to a four year follow-up, ${ }^{15,16}$ although this may not be true of carotid angioplasty alone. ${ }^{17}$

In two large prospective multicenter observational cohorts in high-surgical risk patients, carotid stenting has demonstrated real-world outcomes consistent with established guidelines for carotid endarterectomy in both symptomatic and asymptomatic nonoctogenarian patients. ${ }^{18,19}$ Currently for patients with asymptomatic carotid stenosis who are considered at high surgical risk, carotid stenting can be performed with equivalent short-term and long-term results in terms of stroke, death, and myocardial infarction when compared with carotid endarterectomy. ${ }^{20}$ The preliminary results from CREST, the largest prospective randomized trial comparing CEA and CAS which included 1321 symptomatic and 1181 asymptomatic patients from 117 US and Canadian centers show a nonsignificant difference $(7.2 \%$ for stenting vs. $6.8 \%$ for surgery) in the composite primary endpoint of any stroke, myocardial infarction (MI), or death during the periprocedural period or ipsilateral stroke on four year follow-up. ${ }^{21}$ We report our experience of treating asymptomatic carotid disease patients with carotid stenting in a routine clinical setting over a decade.

\section{Methods}

This is a retrospective cohort study of patients who underwent carotid angioplasty and stenting at the Foothills Medical Center,
Calgary, Canada between 1997 and 2007. The qualifying event, demographic and stroke risk factors, treatment history including the use of antiplatelets, statins and anti coagulants were obtained through chart review. The qualifying events were categorized as symptomatic and asymptomatic by the treating physicians. Transient ischemic attack (TIA) (defined as any focal neurological deficit caused by cerebral ischemia that resolved within 24 hours from onset), retinal event - (defined as transient or permanent monocular vision loss ipsilateral to carotid stenosis), and ipsilateral ischemic stroke were considered symptomatic events. Patients who did not have stroke, transient cerebral ischemia or relevant neurological symptoms referable to the ipsilateral carotid artery stenosis in the preceding six months were considered asymptomatic.

The cause and degree of stenosis, and the stent type were recorded. The degree of stenosis preprocedure was determined primarily by the computed tomogram (CT) angiography, but also by duplex ultrasound or magnetic resonance angiography of the neck vessels. The degree of stenosis was defined using the North American Symptomatic Carotid Endarterectomy Trial (NASCET) criteria applied to CT source images as well as reconstructed sagittal/coronal tomographic images from $\mathrm{CT}$, and categorized into moderate (50 to $70 \%$ stenosis), severe (more than $70 \%$ ) and near occlusion (more than $95 \%$ stenosis with collapsed distal internal carotid artery [ICA]). The procedure was considered to be high risk if patients had these characteristics: significant cardiac disease, severe pulmonary disease, contralateral carotid occlusion, previous neck surgery or radiation, age of 80 years or more, or recurrent carotid stenosis after carotid endarterectomy. Significant cardiac disease was defined by a prior history of coronary angioplasty or cardiac bypass surgery. Severe pulmonary disease was defined as any pulmonary disease requiring home oxygen therapy. The procedures were performed by experienced neurointerventionalists. The decision regarding stenting versus endarterectomy was taken by the treating team (Neurointerventionalist, Neurosurgeon, and Stroke Neurologist) and after discussion with the patient. Patients who had major medical co-morbidities and high-risk anatomic patterns of carotid vasculature (eg. surgically inaccessible stenosis, inadequate collateral circulation) underwent stenting. Informed consent was obtained from all patients.

Carotid stenting was performed under conscious local anaesthesia. Patients were premedicated with Aspirin and Clopidogrel. Intravenous Heparin bolus was given to patients prior to the procedure and a femoral access route was used. Distal protection devices were used in all cases from 1999 onward and the device most commonly used was the FilterWire EZ Embolic Protection System (Boston Scientific, Natick MA). All patients underwent pre-dilatation with balloon angioplasty prior to stenting. Carotid WallStent (Boston Scientific, Natick MA), Acculink (Guidant, Santa Clara CA, USA), Precise (Cordis, Miami FL, USA), and Protege (ev3 Inc., Plymouth Minnesota) stents were used. Patients were admitted to a close observation stroke unit for the first 24-hours after the procedure. Clopidogrel was discontinued after two months and it was recommended that Aspirin be continued lifelong in all patients.

The primary outcome was stroke or death at 30 days. Stroke was defined as a new focal neurological deficit of presumed 
Table 1: Risk factors and medications

\begin{tabular}{|c|c|c|c|}
\hline Risk Factor and Medications & $\begin{array}{l}\text { Symptomatic group } \\
(\mathrm{n}=214)(\%)\end{array}$ & $\begin{array}{l}\text { Asymptomatic group } \\
(\mathrm{n}=41)(\%)\end{array}$ & $p$ value \\
\hline Age & $73.2 \pm 8.9$ & $66.0 \pm 8.8$ & $<0.0001$ \\
\hline Female Gender & $56(22.0 \%)$ & $11(26.8 \%)$ & 0.85 \\
\hline Octogenarians & $59(27.6 \%)$ & $2(4.9 \%)$ & 0.002 \\
\hline Severe stenosis (>70\%) & $120(56.1 \%)$ & $39(95.1 \%)$ & $<0.0001$ \\
\hline Coronary Artery Disease & $104(48.6 \%)$ & $17(41.5 \%)$ & 0.50 \\
\hline Myocardial Infarction & $69(32.2 \%)$ & $12(29.3 \%)$ & 0.72 \\
\hline Chronic Obstructive Pulmonary Disease & $38(17.8 \%)$ & $6(14.6 \%)$ & 0.66 \\
\hline Diabetes Mellitus & $52(24.3 \%)$ & $17(41.5 \%)$ & 0.04 \\
\hline Peripheral Vascular Disease & $34(15.9 \%)$ & $9(22.0 \%)$ & 0.37 \\
\hline Hypertension & $177(82.7 \%)$ & $36(87.8 \%)$ & 0.82 \\
\hline Smoking & $64(29.9 \%)$ & $12(29.3 \%)$ & 1.00 \\
\hline Aspirin & $202(94.4 \%)$ & $39(95.1 \%)$ & 1.00 \\
\hline Clopidogrel & $195(91.1 \%)$ & $40(97.6 \%)$ & 0.22 \\
\hline Statin & $138(64.5 \%)$ & $30(73.2 \%)$ & 0.49 \\
\hline Warfarin & $38(17.8 \%)$ & $6(14.6 \%)$ & 0.66 \\
\hline Median hospital stay (days) & $2(1-3)$ & $2(1-4)$ & 0.16 \\
\hline
\end{tabular}

vascular origin persisting more than 24 hours, supported by appropriate findings on radiological imaging. Stroke was considered major if hospitalization was required or prolonged. Neurologic death was defined as death related to a massive stroke or intracerebral hemorrhage $(\mathrm{ICH})$. Patients were followed up in the stroke clinic and were examined by a stroke neurologist at 30 days. When the 30-day follow up data was not available, the vital status of the individual at that time was sought. Intraprocedural complications were defined as complications that occurred during the procedure. The study was approved by the institutional review board.

The data are reported using standard descriptive statistics. Continuous variables were expressed as absolute numbers and percentages. All proportions were assessed using the Fisher's test. Wilcoxon rank sum test was used to compare categorical variables. Statistical significance was fixed at $p<0.05$.

\section{ReSUlts}

A total of 243 patients underwent 255 carotid stenting procedures. Their ages ranged from 50 to 83 years; the mean age (SD) was $72(9.3)$ years and 67 (26.3\%) were women. Forty one patients $(16.1 \%)$ were asymptomatic. Asymptomatic patients were younger and had similar risk factors to the symptomatic cohort (Table 1). Nine (22.0\%) asymptomatic and $43(20.1 \%)$ symptomatic patients had two or more features that were considered high risk for the procedure. The etiology of carotid stenosis in the asymptomatic group and the indications for carotid stenting are shown (Table 2).
One patient $(2.4 \%)$ was enrolled into the CREST ${ }^{21}$ lead-in phase and one $(2.4 \%)$ into the MAVERIC study. ${ }^{22}$ The median duration between symptom onset and carotid stenting was 8.6 (18.9) weeks. The number of patients who underwent stenting within two weeks of symptom onset was 59 (27.6\%).

Thirty-day follow up data were available in 244 patients $(95.7 \%)$. One intraprocedural minor stoke characterized by clumsiness of the right hand and minor word finding difficulty was noted in the asymptomatic group, the patient recovered completely neurologically at 30-day follow-up. Eight deaths $(3.7 \%)$, six major strokes $(2.8 \%)$ and seven minor strokes $(3.3 \%)$ occurred in the symptomatic group $(\mathrm{p}=0.22)$ (Table 3). Two patients $(0.9 \%)$ in the symptomatic group sustained myocardial infarction. Transient neurologic dysfunction was found in one patient $(2.4 \%)$ in the asymptomatic group and in four patients $(1.9 \%)$ in the symptomatic group. However the exact mechanism could not be ascertained as investigations including electroencephalogram and brain and carotid imaging turned out to be normal. Hyperperfusion syndrome was seen in one patient $(2.4 \%)$ in the asymptomatic group and in two patients $(0.9 \%)$ in the symptomatic group. Details regarding the diagnosis of hyperperfusion syndrome have been previously described. ${ }^{23}$ Asymptomatic bradycardia was found in six symptomatic and in one asymptomatic patient intraprocedurally. Asymptomatic hypotension was witnessed in three symptomatic and one asymptomatic patient. No other peri-procedural complications such as retroperitoneal hematoma, arterial dissection/vessel injury, contrast reaction occurred in the asymptomatic cohort. 
Table 2: Indications for carotid stenting and etiology of carotid stenosis in asymptomatic group

Indications for carotid stenting

\begin{tabular}{ll}
\hline Progressive stenosis & $16(39.0 \%)$ \\
\hline Bilateral severe stenosis & $14(34.2 \%)$ \\
\hline Access for another endovascular procedure & $3(7.3 \%)$ \\
\hline For improving collaterals & $3(7.3 \%)$ \\
\hline Isolated circulation & $2(4.9 \%)$ \\
\hline Prior to coronary artery bypass graft & $2(4.9 \%)$ \\
\hline Incidental detection of retinal emboli & $1(2.4 \%)$ \\
\hline Recurrent Stenosis after carotid endarterectomy & $5(12.2 \%)$ \\
\hline Recurrent Stenosis after carotid stenting & $6(14.6 \%)$
\end{tabular}

Etiology of Carotid Stenosis

\begin{tabular}{ll}
\hline Atherosclerosis & $36(87.8 \%)$ \\
\hline Radiation induced stenosis & $3(7.3 \%)$ \\
\hline Fibromuscular dysplasia & $2(4.9 \%)$ \\
\hline
\end{tabular}

There was a trend towards a decline in the periprocedural complications with time for the combined cohort (Figure). The periprocedural complication rate from 2002 to 2007 was $7 \%$ $(16 / 229) ; 31.2 \%$ of these patients had minor stroke and had $\mathrm{mRS} \leq 1$ at 30 -day follow-up. If only major strokes and deaths were considered, the periprocedural complication rate 2002 onwards was $4.8 \%(11 / 229)$.

\section{Discussion}

A key determinant of whether or not carotid artery revascularization is appropriate will depend upon both the periprocedural safety and long-term outcomes. Our study suggests that in selected patients, carotid stenting for asymptomatic patients is safe. Only one patient suffered a minor stroke, but had an excellent 30-day neurological outcome. No deaths or cardiac events occurred in asymptomatic patients.

Although the rates of periprocedural events were high in our series in the initial years, the outcome events decreased from 2002 onwards. This suggests a learning curve ${ }^{24}$ and additionally reflects practice patterns; in the initial years stenting was reserved for patients with significant co-morbidities who were not fit surgical candidates and in the later years stenting was offered to more and more patients routinely.

The main indication for carotid revascularization in asymptomatic patients is to prevent 'artero-embolic' stroke which is the usual cause of stroke in atherosclerotic carotid disease. Impaired cerebral vasomotor reactivity, altered collateral pattern and consequent strokes secondary to carotid stenosis have been demonstrated by several studies. ${ }^{25,26}$ Accordingly progressive stenosis and poor collateral flow were indications for carotid stenting in some of our patients.

Our study compares favorably with similar studies. The preliminary results from the CREST suggest a similar outcome for asymptomatic patients. ${ }^{21}$ In the combined data from two recent large multicenter prospective carotid stenting trials consisting of 6320 patients, in the population comparable with American Heart Association guidelines ( $<80$ years), the combined 30-day death and stroke rate was $2.9 \%$ for asymptomatic patients. ${ }^{19}$ In their study, $75 \%$ of the strokes in the asymptomatic non-octogenarian population were minor ones. The 30-day stroke or death rate was $4.8 \%$ in the SAPPHIRE study. ${ }^{12}$ In a US study, both symptomatic and asymptomatic patients had a similar 30 day stroke and death rate of $8.1 \% .^{27}$ This difference between our study and the study by Roubin could be accounted for partly by the technical differences such as the non-use of distal protection devices in their study. Three-fourths $(558 / 747)$ of the BEACH registry ${ }^{28}$ patients were asymptomatic with a carotid stenosis between 80 and $99 \%$; the 30 day major adverse events was $5.0 \%$. Major adverse events were noted in $4.7 \%$ of the asymptomatic patients in the CASES-PMS study. ${ }^{29}$ Higher 30-day events in these studies could be accounted for by the fact that all were high risk patients secondary to anatomic factors or medical co-morbidities, whereas only $26.8 \%$ of our cohort consisted of high-risk patients. A 30-day complication rate of $4.60 \%$ in the asymptomatic group compared to $7.13 \%$ in the symptomatic group was witnessed in a study by Sidawy. ${ }^{30}$

In the REACH registry, the rate of cerebrovascular events (TIAs and all strokes) was highest in patients with asymptomatic carotid stenosis (ACAS). ${ }^{31}$ Across the three patient groups ACAS vs. no ACAS vs. unknown carotid artery status, the rates of cerebrovascular events at one year were $5.73 \%$ vs. $3.30 \%$ vs. $2.55 \%(\mathrm{P}<0.0001)$. Approximately $70 \%$ of patients with ACAS received statins, $87 \%$ were treated with antihypertensive drugs and even more patients were receiving antithrombotic drugs at baseline. Hence the real world stroke risk in spite of medical management appears to be much higher in patients with ACAS than previously appreciated.

Octogenarians generally have a higher complication rate secondary to technical difficulties like increased tortuosity of the

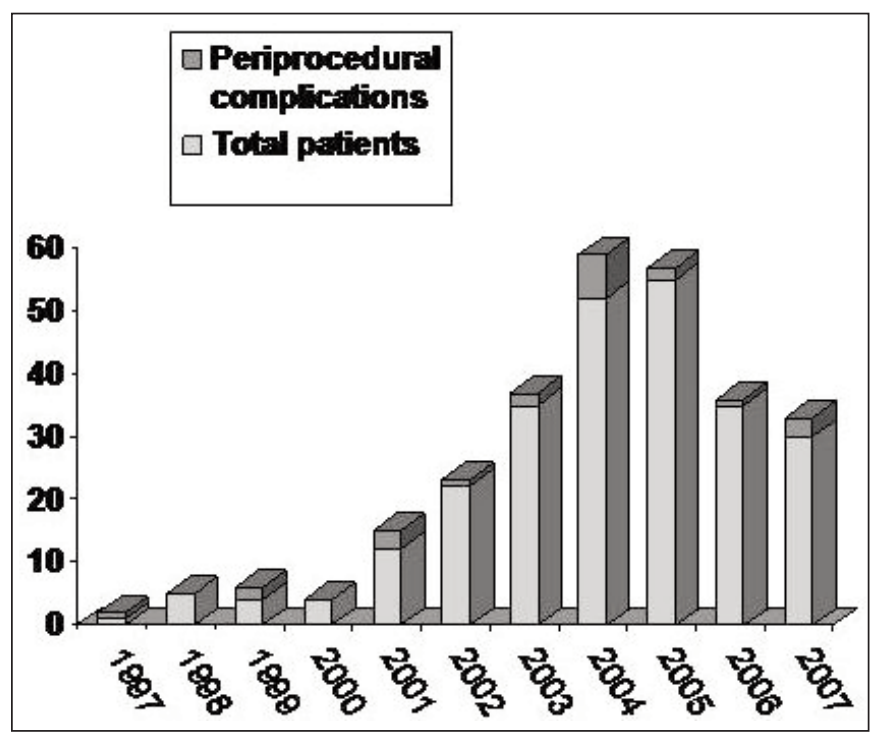

Figure: Number of periprocedural complications by year of procedure. 
Table 3: Intraprocedural events $\dagger$ and 30-day outcome

\begin{tabular}{|c|c|c|c|}
\hline & Asymptomatic group $(n=41)(\%)$ & Symptomatic group $(\mathrm{n}=214)(\%)$ & p value \\
\hline \multicolumn{4}{|c|}{ Intraprocedural Events } \\
\hline Asymptomatic dissection & $0(0 \%)$ & $5(2.3 \%)$ & 1.00 \\
\hline Transient neurologic dysfunction & $0(0 \%)$ & $2(0.9 \%)$ & 1.00 \\
\hline Minor stroke & $1(2.4 \%)$ & $1(0.5 \%)$ & 0.30 \\
\hline Major stroke & $0(0 \%)$ & $1(0.5 \%)$ & 1.00 \\
\hline Cardiac sysrhythmia & $0(0 \%)$ & $7(3.3 \%)$ & 0.60 \\
\hline Hemodynamic instability & $0(0 \%)$ & $4(1.9 \%)$ & 1.00 \\
\hline \multicolumn{4}{|c|}{30 day outcome } \\
\hline Mortality (any cause) & $0(0 \%)$ & $8(3.7 \%)$ & 0.36 \\
\hline Neurologic death & $0(0 \%)$ & $5(2.3 \%)$ & 1.00 \\
\hline Non-neurologic death & $0(0 \%)$ & $3(1.4 \%)$ & 1.00 \\
\hline Major stroke & $0(0 \%)$ & $6(2.8 \%)$ & 0.59 \\
\hline Minor stroke & $1(2.4 \%)$ & $7(3.3 \%)$ & 1.00 \\
\hline Major stroke or death & $0(0 \%)$ & $14(6.5 \%)$ & 0.14 \\
\hline All stroke and death & $1(2.4 \%)$ & $21(9.8 \%)$ & 0.22 \\
\hline Transient neurologic deficit & $1(2.4 \%)$ & $4(1.9 \%)$ & 0.59 \\
\hline Myocardial infarction & $0(0 \%)$ & $2(0.9 \%)$ & 1.00 \\
\hline Hyperperfusion syndrome & $1(2.4 \%)$ & $2(0.9 \%)$ & 0.41 \\
\hline Missing & $3(7.3 \%)$ & $8(3.7 \%)$ & 0.39 \\
\hline
\end{tabular}

$\dagger$ Intraprocedural events have been counted again as 30 day events

arteries, and a higher risk of embolization from extensive atherosclerotic changes in the aorta. There were a higher number of octogenarians in the symptomatic group compared to the asymptomatic group in our cohort $(p=0.002)$. Higher number of adverse events occurred in the octogenarians in the study by Roubin. ${ }^{27}$ Gray also reports higher stroke and death rate in the asymptomatic octogenarian group compared to the younger group. ${ }^{19}$ In our study, however, octogenarians had an outcome similar to the non octogenarians. There were no significant differences in outcome between the two genders in our study, and the study by Roubin. ${ }^{27}$ In the ICSS, women had equivalent results with stenting due to high complication rates with surgery. ${ }^{14}$ Further studies on the issues of sex-differences and age-differences in carotid stenting vs. endarterectomy are needed.

The SAPPHIRE trial noted a similar incidence of stroke or death at 30 days for patients with asymptomatic carotid stenosis who underwent stenting (5.4\%) compared with patients who underwent carotid endarterectomy $(4.6 \%) .{ }^{16}$ Several studies have demonstrated that carotid artery stent placement can be performed with a complication rate that is similar to that of conventional surgery. ${ }^{27,32,33}$ Although the 30 day safety data from the recent ICSS trial favored carotid endarterectomy over carotid stenting, asymptomatic patients were excluded from this trial. ${ }^{14}$

This is a retrospective study and the data quality depends on the accuracy of documentation in charts. We do not have long- term follow-up of these patients to comment on the durability of the procedure. Nevertheless, we feel our experience contributes to the data on peri-procedural safety of stenting encouraging neurointerventionists to perform stenting in routine clinical scenario. Our view is that among selected asymptomatic patients carotid intervention is both warranted and can be conducted safely with carotid stenting.

\section{Disclosure}

The Calgary Stroke Program has been a participating site in the MAVERIC trial, ICSS, and CREST which are all trials examining carotid artery stenting.

\section{REFERENCES}

1. Gorelick PB, Sacco RL, Smith DB, et al. Prevention of a first stroke: a review of guidelines and a multidisciplinary consensus statement from the National Stroke Association. JAMA. 1999; 281:1112-20

2. Meyers PM, Schumacher HC, Tanji K, Higashida RT, Caplan LR. Use of stents to treat extracranial cerebrovascular disease. Annu Rev Med. 2007; 58:107-22.

3. Sacco RL, Benjamin EJ, Broderick JP, et al. American Heart Association Prevention Conference IV. Prevention and rehabilitation of stroke risk factors. Stroke. 1997; 28:1507-17.

4. Chambers BR, Norris JW. Outcome in patients with asymptomatic neck bruits. N Engl J Med. 1986; 315:860-5. 
5. The North American Symptomatic Carotid Endarterectomy Trial Collaborators. Beneficial effect of carotid endarterectomy in symptomatic patients with high-grade carotid stenosis. N Engl J Med. 1991; 325:445-53.

6. Hobson RW, Weiss DG, Fields Goldstone J, et al. Efficacy of carotid endarterectomy for asymptomatic carotid stenosis. N Engl J Med. 1993; 328:221-7.

7. Executive Committee for the Asymptomatic Carotid Atherosclerosis Study. Endarterectomy for asymptomatic carotid artery stenosis. JAMA. 1995; 273(18):1421-8.

8. Halliday A, Mansfield A, Marro J, et al. Prevention of disabling and fatal strokes by successful carotid endarterectomy in patients without recent neurological symptoms: randomized controlled trial. Lancet. 2004; 363:1491-502.

9. Perry JR, Norris JW. Asymptomatic carotid artery stenosis. Arch Neurol. 1997; 54(7):799-800.

10. CAVATAS Investigators. Endovascular versus surgical treatment in patients with carotid stenosis in the Carotid and Vertebral Artery Transluminal Angioplasty Study (CAVATAS): a randomized trial. Lancet. 2001; 357(9270):1729-37.

11. Yadav JS, Wholey MH, Kuntz RE, et al. Protected carotid-artery stenting versus endarterectomy in high-risk patients. N Engl J Med. 2004; 351:1493-501.

12. SPACE Collaborative Group. Ringleb PA, Allenberg J, Brückmann $\mathrm{H}$, et al. 30 day results from the SPACE trial of stent-protected angioplasty versus carotid endarterectomy in symptomatic patients: a randomized non-inferiority trial. Lancet. 2006; 368: 1239-47.

13. Mas JL, Chatellier G, Beyssen B, et al. Endarterectomy versus stenting in patients with symptomatic severe carotid stenosis. N Engl J Med. 2006; 355:1660-71.

14. International Carotid Stenting Study investigators, Ederle J, Dobson $\mathrm{J}$, et al. Carotid artery stenting compared with endarterectomy in patients with symptomatic carotid stenosis (International Carotid Stenting Study): an interim analysis of a randomised controlled trial. Lancet. 2010; 375(9719):985-97.

15. Mas JL, Trinquart L, Leys D, et al. Endarterectomy Versus Angioplasty in Patients with Symptomatic Severe Carotid Stenosis (EVA-3S) trial: results up to 4 years from a randomised, multicentre trial. Lancet Neurol. 2008; 7(10):885-92.

16. Gurm HS, Yadav JS, Fayad P, et al. Long-term results of carotid stenting versus endarterectomy in high-risk patients. N Engl J Med. 2008; 358(15):1572-9.

17. Bonati LH, Ederle J, McCabe DJ, et al. Long-term risk of carotid restenosis in patients randomly assigned to endovascular treatment or endarterectomy in the Carotid and Vertebral Artery Transluminal Angioplasty Study (CAVATAS): long-term followup of a randomised trial. Lancet Neurol. 2009; 8(10):908-17.

18. Chung J, Shin YS, Lim YC, Park SK. The clinical outcomes of 75 consecutive patients with cervical carotid artery stenosis treated by carotid artery stenting. J Korean Neurosurg Soc. 2009; 45(6): $350-4$
19. Gray WA, Chaturvedi S, Verta P; Investigators and the Executive Committees. Thirty-day outcomes for carotid artery stenting in 6320 patients from 2 prospective, multicenter, high-surgical-risk registries. Circ Cardiovasc Interv. 2009; 2(3):159-66.

20. Oderich GS. Commentary on "a review of the trials comparing carotid endarterectomy and carotid angioplasty and stenting". Perspect Vasc Surg Endovasc Ther. 2008; 20(3):309-10.

21. Brott TG, Hobson RW, Howard G, Roubin GS, Clark WM, Brooks $\mathrm{W}$, et al for the CREST Investigators. Stenting Compared to Endarterectomy for Treatment of Carotid Artery Stenosis. NEJM 2010; 363(1):11-23 .

22. Hill MD, Morrish W, Soulez G, et al. Multicenter evaluation of a self-expanding carotid stent system with distal protection in the treatment of carotid stenosis. AJNR. 2006; 27:759-65.

23. Coutts SB, Hill MD, Hu WY. Hyperperfusion syndrome: toward a stricter definition. Neurosurgery. 2003 Nov; 53(5):1053-8.

24. Verzini F, De Rango P, Parlani G, Panuccio G, Cao P. Carotid artery stenting: technical issues and role of operators' experience. Perspect Vasc Surg Endovasc Ther. 2008; 20(3):247-57.

25. Gur AY, Bova I, Bornstein NM. Is impaired cerebral vasomotor reactivity a predictive factor of stroke in asymptomatic patients? Stroke. 1996; 27:2188-90.

26. Reinhard M, Müller T, Guschlbauer B, Timmer J, Hetzel A. Dynamic cerebral autoregulation and collateral flow patterns in patients with severe carotid stenosis or occlusion. Ultrasound Med Biol. 2003; 29:1105-13.

27. Roubin GS, New G, Iyer SS, et al. Immediate and late clinical outcomes of carotid artery stenting in patients with symptomatic and asymptomatic carotid artery stenosis: a 5-year prospective analysis. Circulation. 2001; 103(4):532-7.

28. White CJ, Iyer SS, Hopkins LN, Katzen BT, Russell ME; BEACH Trial Investigators. Carotid stenting with distal protection in high surgical risk patients: the BEACH trial 30 day results. Catheter Cardiovasc Interv. 2006; 67(4):503-12.

29. Katzen BT, Criado FJ, Ramee SR, et al. Carotid artery stenting with emboli protection surveillance study: thirty-day results of the CASES-PMS study. Catheter Cardiovasc Interv. 2007; 70(2): 316-23.

30. Sidawy AN, Zwolak RM, White RA, et al. Risk-adjusted 30-day outcomes of carotid stenting and endarterectomy: results from the SVS Vascular Registry. J Vasc Surg. 2009; 49(1):71-9.

31. Aichner FT, Topakian R, Alberts MJ, et al. High cardiovascular event rates in patients with asymptomatic carotid stenosis: the REACH Registry. Eur J Neurol. 2009; 16(8):902-8.

32. Wholey $\mathrm{MH}$, Wholey $\mathrm{M}$, Mathias $\mathrm{K}$, et al. Global experience in cervical carotid artery stent placement. Catheter Cardiovasc Interv. 2000; 50(2):160-7.

33. Cremonesi A, Manetti R, Setacci F, Setacci C, Castriota F. Protected carotid stenting: clinical advantages and complications of embolic protection devices in 442 consecutive patients. Stroke. 2003; 34:1936-41 